\title{
HEALTH AND ENVIRONMENT THROUGH KITCHEN WASTE MANAGEMENT
}

\author{
Sadhana D. Bhoyar \\ Department of Resource Management, Home Science Faculty, \\ Sevadal Mahila Mahavidyalaya, Nagpur-440024
}

\begin{abstract}
:
In the present study fruit class vegetable tomato was grown on manure prepared from kitchen waste and normal soil in pots and sensory evaluation was done in Post Graduate Department of Home Science. Recipe was formulated and evaluated. Three trials $\mathrm{T}_{1}, \mathrm{~T}_{1}$ and $\mathrm{T}_{3}$ were conducted for testing of various sensory characteristics such as appearance, colour, texture, taste, flavour and acceptability. For this five Judges were selected. Soup of tomato was prepared. The recipe was standardized. Based on the mean values results were tabulated and analyzed statistically by applying ' $\mathrm{t}$ ' test. It was observed that kitchen waste variety scored maximum than normal soil. It showed highly significant difference in both the varieties when compared on organoleptic characteristics. Thus, it was concluded that kitchen waste manure variety was highly appreciated and more superior in all the sensory characters over normal soil. Thus by using organic manure like kitchen waste manure we can save our environment as well as health.
\end{abstract}

Keywords: kitchen waste manure, sensory characteristics, standardization

\section{INTRODUCTION:}

Waste is a by-product of human activity and is generally assumed to be useless remains, having no value in its present state. For our survival we need food, water, clothing and shelter. However we consume many things apart from these basic requirements. More consumption generates more waste. Everyday we throw away kitchen waste into the trash can. These kitchen waste i.e. vegetables and fruit peels, egg shells, used tea powder are full of nutrients that end up in landfills to be never be reused again. However, it can be recycled into yard in form of manure.

Household waste management is an issue not to be ignored. In the wake of rapidly depleting natural resources of health hazards caused by the huge amount of waste produced, recovery and reuse have become inevitable in the present scenario. Another important point to note is that the natural recycling period is very long compared with the human life span and the 
society is interested in recycling on a time scale. It is clear that new methods of water reclamation and reuse must be developed.

Though in many cities, the urban waste is managed by the city corporation, it is still ineffective unless each small family takes the responsibility and care for their own waste produced. So composting kitchen waste in form of rich manure is need of today. Many fancy names can be given to the attempts one make for converting a waste to a resource - cash from trash, dollars from dirt, money from muck, gold from garbage, rupees from rubbish, value from waste etc. It sounds exciting, but is easier said than done. It is one thing to develop a method of converting any waste to a valuable product on laboratory scale, it is quite another thing to do so economically and on a large scale. In spite of so much talk about 'waste utilization', large quantities of waste still go unutilized. This not only leaves the problems of waste disposal in our hands but also leaves for us the problems caused by such spin offs as mosquitoes, rodents and plague.

\section{OBJECTIVES:}

1) To overcome the issue of waste management by preparing manure and growing vegetables on it.

2) To test the palatability of tomato grown on kitchen waste manure and normal soil.

\section{REVIEW OF LITERATURE:}

Review of literature serves as essential background for any research.

Nakul Bhatiya (2005) undertaken a study on effect of organic manure and bio fertilizers with reduced doses of inorganic fertilizers on growth and yield of Indian bean it showed that FYM was most favorable for producing best vegetable growth, earlier flowering and higher yield of Indian bean.

Poinkar (2004) conducted a study on the effect of organic manure and bio-fertilizers on growth yield and quality of turmeric and showed that application of farmyard manure along with use of bio-fertilizer was beneficial in respect of growth yield and earliness in maturity period.

Shinde (2007) conducted a survey on kitchen waste recycling and the observation were that most of the respondents used kitchen waste that is 
vegetable peeling, leftover foods papers etc. for preparing compost manure in their home.

\section{METHODOLOGY:}

The experimental procedure of the present study was carried out as under:

\section{Experimental Procedure}

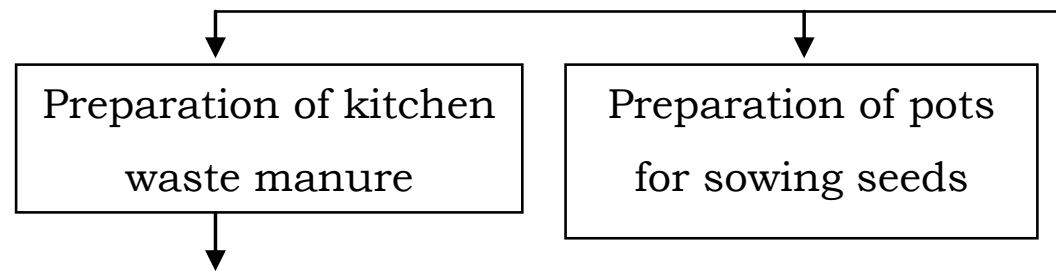

- Selection of place

- Material required for preparation of manure

- Collection of waste vegetables

- Mixing vegetables with soil

- Covering the mixture

- Watering the mixture

- Selection of equipments

Preparation of recipes for sensory evaluation

- Selection of place

- Selection of time

- Selection of recipes

- Standardization of recipes

- Method of preparation

- Procurement of ingredients

- Sensory evaluation

- Portability

- Evaluation test

- Selection of judges

- Score Card development

- Scores

Materials and methods for making the kitchen waste manure:

Tank method was followed for preparing the manure. The different steps followed for preparing manure from kitchen waste.

Collection of Kitchen Waste: The kitchen waste including vegetable, fruit peels, egg shells, tea powder excluding oily items were collected in a bin every day. Nearly $1 / 2$ to $1 \mathrm{Kg}$ waste was collected daily.

> Preparation of mixture: Collected kitchen waste was spread at the bottom of the tank. One layer of soil and other layer of kitchen waste likewise for one month. The entire bed was covered with gunny bags. This 
was essential to afford protection to the waste from flies and to maintain the optimum moisture level in the bed. Watering was done to maintain moisture level in the beds.

The manure was ready in 50 days.

Sensory Evaluation: It was done on the basis of organoleptic characteristics of spinach soup. It was prepared using fresh spinach, ploughed from the experimental pots grown on kitchen waste manure and normal soil. Statistical appraisal of data was calculated by using mean/average, ' $\mathrm{t}$ ' test and graphical representation.

Null Hypothesis: There is no real difference between the sensory characteristic of two varieties of spinach grown on kitchen waste manure and normal soil and if it is, it is just by chance.

\section{RESULT AND DISCUSSION:}

The findings of study are presented under following heads.

Table I shows that the appearance of tomato soup (K) variety had scored 9.9 and (C) variety scored 8.6 which showed highly significant difference. It was statistically proved significant when compared on organoleptic characteristics. Hence, it can be conclude that (K) was more superior over (C) variety.

Table II shows that the color of spinach soup (K) variety had scored 9.9 and (C) variety scored 8.3 which showed highly significant difference. It was statistically proved significant when compared on organoleptic characteristics. Hence, it can be conclude that $(\mathrm{K})$ was more superior over (C) variety.

Table III shows that the consistency of tomato soup (K) variety had scored 8.9 and (C) variety scored 7.1 which showed highly significant difference. It was statistically proved significant when compared on organoleptic characteristics. Hence, it can be conclude that $(\mathrm{K})$ was more superior over $(\mathrm{C})$ variety.

Table IV shows that the taste of tomato soup $(\mathrm{K})$ variety had scored 8.7 and (C) variety scored 7.5 which showed highly significant difference. It was statistically proved significant when compared on organoleptic 
characteristics. Hence, it can be conclude that $(\mathrm{K})$ was more superior over (C) variety.

Table V shows that the flavour of tomato soup $(\mathrm{K})$ variety had scored 9.6 and $(\mathrm{C})$ variety scored 8.2 which showed highly significant difference. It was statistically proved significant when compared on organoleptic characteristics. Hence, it can be conclude that $(K)$ was more superior over (C) variety.

Table VI shows that the acceptability of tomato soup $(\mathrm{K})$ variety had scored 9.3and (C) variety scored 8.2 which showed highly significant difference. It was statistically proved significant when compared on organoleptic characteristics. Hence, it can be conclude that $(K)$ was more superior over (C) variety.

\section{CONCLUSION:}

The problem of disposal of household kitchen waste can be solved by utilizing it for preparing manure.

V Vegetables grown on this compost are healthy, highly nutritious and no harmful residues are left in the soil.

I It helps to work as much as possible within a close system with regard to organic matter and nutrient elements.

口 It will be helpful to earn some money by utilizing kitchen waste as manure.

This will also be helpful in preventing environmental pollution.

- This technique can be popularized among masses by organizing workshops, exhibitions, demonstrations and other such activities.

Table I: Appearance of Tomato Soup

\begin{tabular}{|l|l|l|l|l|l|l|l|l|}
\hline & \multicolumn{3}{|l|}{ Kitchen Waste Manure (K) } & & \multicolumn{3}{l|}{ Normal Soil (C) } & \\
\hline Judges & T1 & T2 & T3 & Mean score & T1 & T2 & T3 & Mean score \\
\hline J1 & 10 & 10 & 10 & 10.0 & 8 & 9 & 9 & 8.7 \\
\hline J2 & 10 & 10 & 10 & 10.0 & 10 & 8 & 8 & 8.7 \\
\hline J3 & 10 & 10 & 10 & 10.0 & 8 & 10 & 10 & 9.3 \\
\hline J4 & 8 & 10 & 10 & 9.3 & 6 & 8 & 8 & 7.3 \\
\hline J5 & 10 & 10 & 10 & 10.0 & 10 & 8 & 9 & 9.0 \\
\hline & Mean & & & 9.9 & & & & 8.6 \\
\hline & SD & & & 0.3 & & & & 0.8 \\
\hline & t-value $=3.92^{*}$ & & & & & & & \\
\hline
\end{tabular}


Table II: Colour of Tomato Soup

\begin{tabular}{|l|l|l|l|l|l|l|l|l|}
\hline & \multicolumn{2}{|l|}{$\begin{array}{l}\text { Kitchen Waste Manure } \\
\text { (K) }\end{array}$} & \multicolumn{5}{|l|}{$\begin{array}{l}\text { Normal Soil } \\
\text { (C) }\end{array}$} \\
\hline Judges & T1 & T2 & T3 & $\begin{array}{l}\text { Mean } \\
\text { score }\end{array}$ & T1 & T2 & T3 & Mean score \\
\hline J1 & 10 & 10 & 10 & 10.0 & 10 & 8 & 10 & 9.3 \\
\hline J2 & 10 & 10 & 10 & 10.0 & 10 & 8 & 9 & 9.0 \\
\hline J3 & 10 & 10 & 10 & 10.0 & 8 & 8 & 9 & 8.3 \\
\hline J4 & 8 & 10 & 10 & 9.3 & 6 & 6 & 8 & 6.7 \\
\hline J5 & 10 & 10 & 10 & 10.0 & 8 & 8 & 8 & 8.0 \\
\hline & Mean & & & 9.9 & & & & 8.3 \\
\hline & SD & & & 0.3 & & & & 1.0 \\
\hline & t-value= 3.74* & & & & & & & \\
\hline
\end{tabular}

Table III: Consistency of Tomato Soup

\begin{tabular}{|l|l|l|l|l|l|l|l|l|}
\hline & \multicolumn{3}{|l|}{$\begin{array}{l}\text { Kitchen Waste Manure } \\
\text { (K) }\end{array}$} & \multicolumn{3}{|l|}{$\begin{array}{l}\text { Normal Soil } \\
\text { (C) }\end{array}$} \\
\hline Judges & T1 & T2 & T3 & Mean score & T1 & T2 & T3 & Mean score \\
\hline J1 & 10 & 9 & 10 & 9.7 & 8 & 9 & 8 & 8.3 \\
\hline J2 & 8 & 10 & 8 & 8.7 & 8 & 7 & 8 & 7.7 \\
\hline J3 & 8 & 10 & 8 & 8.7 & 8 & 7 & 9 & 8.0 \\
\hline J4 & 8 & 8 & 10 & 8.7 & 4 & 4 & 4 & 4.0 \\
\hline J5 & 10 & 8 & 8 & 8.7 & 8 & 8 & 7 & 7.7 \\
\hline & Mean & & & 8.9 & & & & 7.1 \\
\hline & SD & & & 0.4 & & & & 1.8 \\
\hline & t-value= 2.39* & & & & & & & \\
\hline
\end{tabular}

Table IV: Taste of Tomato Soup

\begin{tabular}{|l|l|l|l|l|l|l|l|l|}
\hline & \multicolumn{2}{|l|}{$\begin{array}{l}\text { Kitchen } \\
\text { (K) }\end{array}$} & \multicolumn{4}{|c|}{ Waste Manure } & \multicolumn{3}{|l|}{ Normal Soil (C) } & \\
\hline Judges & T1 & T2 & T3 & $\begin{array}{l}\text { Mean } \\
\text { score }\end{array}$ & T1 & T2 & T3 & $\begin{array}{l}\text { Mean } \\
\text { score }\end{array}$ \\
\hline J1 & 8 & 9 & 8 & 8.3 & 8 & 8 & 8 & 8.0 \\
\hline J2 & 8 & 10 & 8 & 8.7 & 8 & 10 & 8 & 8.7 \\
\hline J3 & 10 & 8 & 9 & 9.0 & 8 & 6 & 7 & 7.0 \\
\hline J4 & 6 & 10 & 10 & 8.7 & 6 & 6 & 6 & 6.0 \\
\hline J5 & 8 & 10 & 8 & 8.7 & 8 & 8 & 8 & 8.0 \\
\hline & Mean & & & 8.7 & & & & 7.5 \\
\hline & SD & & & 0.2 & & & & 1.0 \\
\hline & t-value=2.68* & & & & & & & \\
\hline
\end{tabular}


Table V: Flavour of Tomato Soup

\begin{tabular}{|l|l|l|l|l|l|l|l|l|}
\hline & \multicolumn{2}{|l|}{$\begin{array}{l}\text { Kitchen Waste Manure } \\
\text { (K) }\end{array}$} & \multicolumn{4}{|l|}{ Normal Soil (C) } & \\
\hline $\begin{array}{l}\text { Judg } \\
\text { es }\end{array}$ & T1 & T2 & T3 & $\begin{array}{l}\text { Mean } \\
\text { score }\end{array}$ & T1 & T2 & T3 & $\begin{array}{l}\text { Mean } \\
\text { score }\end{array}$ \\
\hline J1 & 10 & 10 & 10 & 10.0 & 8 & 9 & 9 & 8.7 \\
\hline J2 & 8 & 10 & 10 & 9.3 & 10 & 10 & 10 & 10.0 \\
\hline J3 & 10 & 10 & 8 & 9.3 & 7 & 7 & 9 & 7.71 \\
\hline J4 & 8 & 10 & 10 & 9.3 & 4 & 8 & 8 & 6.7 \\
\hline J5 & 10 & 10 & 10 & 10.0 & 8 & 8 & 8 & 8.0 \\
\hline & Mean & & & 9.6 & & & & 8.2 \\
\hline & SD & & & 0.4 & & & & 1.2 \\
\hline & $\begin{array}{l}\text { t-value }= \\
2.74^{*}\end{array}$ & & & & & & & \\
\hline
\end{tabular}

Table VI: Acceptability of tomato soup

\begin{tabular}{|c|c|c|c|c|c|c|c|c|}
\hline$x^{2}$ & $\begin{array}{l}\text { Kitchen } \\
\text { Manure (K }\end{array}$ & & Waste & & Nor & $1 \mathrm{Sc}$ & & \\
\hline Judges & T1 & $\mathrm{T} 2$ & T3 & $\begin{array}{l}\text { Mean } \\
\text { score }\end{array}$ & $\mathrm{T} 1$ & T2 & T3 & $\begin{array}{l}\text { Mean } \\
\text { score }\end{array}$ \\
\hline $\mathrm{J} 1$ & 10 & 9 & 10 & 9.7 & 8 & 9 & 8 & 8.3 \\
\hline $\mathrm{J} 2$ & 10 & 10 & 10 & 10.0 & 10 & 10 & 9 & 9.7 \\
\hline J3 & 10 & 8 & 10 & 9.3 & 8 & 7 & 7 & 7.3 \\
\hline $\mathrm{J} 4$ & 6 & 10 & 9 & 8.3 & 6 & 8 & 8 & 7.3 \\
\hline J5 & 8 & 10 & 9 & 9.0 & 8 & 8 & 9 & 8.3 \\
\hline & Mean & & & 9.3 & & & & 8.2 \\
\hline & $\mathrm{SD}$ & & & 0.6 & & & & 1.0 \\
\hline & $\begin{array}{l}\mathrm{t} \text {-value }= \\
2.33^{*}\end{array}$ & & & & & & & \\
\hline
\end{tabular}




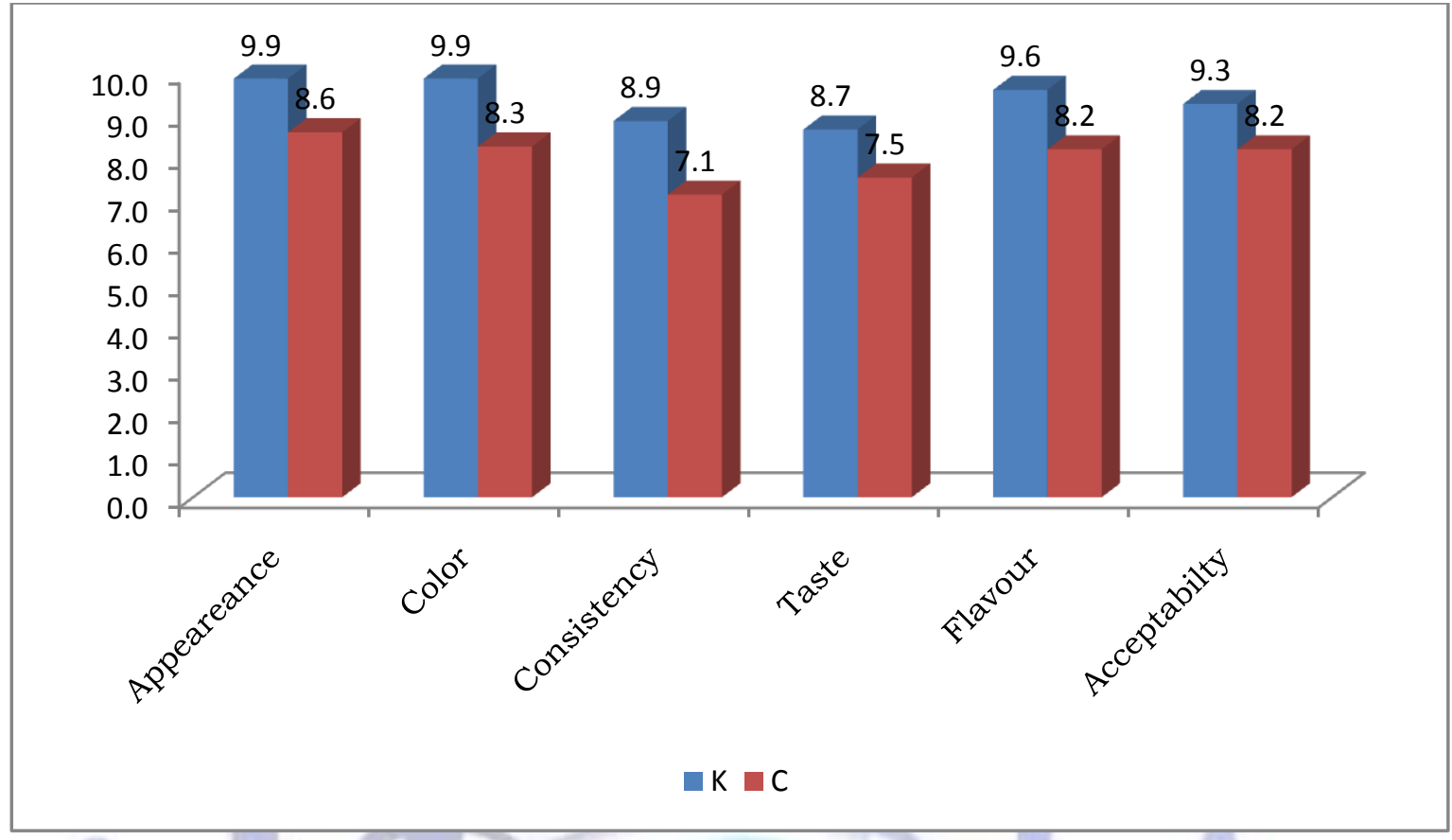

\section{Graph-1: Quality Attributes of Tomato}

\section{REFERENCES:}

- Bhatiya, N. (2005), 'Effect of Organic Manure and Bio-fertilizers with reduced doses of inorganic fertilizers on growth and yield of Indian bean'.

- Poinkar (2004), 'The Effect of Organic Manure and Bio-fertilizers on Growth Yield and Quality of Turmeric', Unpublished M.Sc. (Agriculture) Dissertation, College of Agriculture, Nagpur, Dr. Panjabrao Deshmukh Krishi Vidyapeeth, Akola (M.S.)

- Shinde (2007). 'Kitchen Waste Recycling'. Unpublished M.Sc. (Home Science) Resource Management Dissertation, P.G.T.D. Home Science, R.T.M. Nagpur University, Nagpur.

- Singh, P. and Singh, S. P. (2012). Principles of Vegetable Production, Oxford Book Company, Jaipur, p.1

\section{Websites:}

- http://www.whatwhere \& how.com

- www.wastecap wi.org

- www.http/then.ws/my Chennai 